\begin{tabular}{l} 
SCIENCE \& TECHNOLOGY \\
Journal homepage: http://www.pertanika.upm.edu.my/ \\
\hline PERTANIKA
\end{tabular}

\title{
Identification and Antibiotic Resistance Profile of Salmonella spp. and Citrobacter spp. Isolated from Street-Vended Beverages
}

\author{
Siti Shahara Zulfakar ${ }^{1 *}$, Noraziah Mohamad Zin², Siti Nur Shafika Mat Zalami² \\ and Nur Syakirah Mohd Nawawee ${ }^{1}$ \\ ${ }^{1}$ Environmental Health and Industrial Safety Program, Centre for Toxicology \& Health Risk Studies, Faculty \\ of Health Sciences, Universiti Kebangsaan Malaysia, 50300 UKM, Kuala Lumpur, Malaysia \\ ${ }^{2}$ Programme of Biomedical Science, Faculty of Health Sciences, Universiti Kebangsaan Malaysia, 50300 \\ UKM, Kuala Lumpur, Malaysia
}

\begin{abstract}
The risk of foodborne diseases as well as the dissemination of antibiotic resistant bacteria increases with the consumption of street-vended food and beverages. This study investigated the prevalence of Salmonella spp. and Citrobacter spp. in street-vended beverages sold in Chow Kit, Kuala Lumpur, Malaysia. The Kirby-Bauer disk diffusion method was used to identify the antibiotic resistance profile of Salmonella spp. and Citrobacter spp. isolates towards 11 selected antibiotics. Six beverage samples were found positive for presumptive Salmonella spp. and Citrobacter spp. Upon confirmation via Microgen kit and PCR biochemical testing methods, only one isolate was confirmed to be Salmonella enterica serovar Derby while the other isolates were identified as Citrobacter $\mathrm{spp} .(\mathrm{n}=12$; 2 isolates from each positive beverage sample). The antibiogram test showed that $58.3 \%$, $16.7 \%$, and $8.3 \%$ of the strains tested were resistance to tetracycline, cephalexin, and ampicillin respectively, while all isolates were fully resistant toward penicillin and erythromycin. The isolate with the highest MAR index (0.45) was $\mathrm{S} 23_{1}$, with resistance

ARTICLE INFO

Article history:

Received: 22 July 2020

Accepted: 07 October 2020

Published: 22 January 2021

DOI: https://doi.org/10.47836/pjst.29.1.31

E-mail addresses:

sitishahara.zulfakar@ukm.edu.my (Siti Shahara Zulfakar) noraziah.zin@ukm.edu.my (Noraziah Mohamad Zin)

fikasha096@gmail.com (Siti Nur Shafika Mat Zalami)

nursyakirah_mn@yahoo.com (Nur Syakirah Mohd Nawawee)

* Corresponding author to five of the tested antibiotics (penicillin, erythromycin, tetracycline, cephalexin, and ampicillin). Seven isolates had a MAR index of 0.27 and were resistant to three antibiotics, while the remaining four isolates had the lowest MAR index (0.18) and were resistant to only two antibiotics. This study shows that street-vended beverages have a
\end{abstract}


high risk of spreading antibiotic-resistant bacteria to the public and that Citrobacter spp. should be considered as emerging multidrug-resistant bacteria in the food production system.

Keywords: Antibiotic resistance, beverage, Citrobacter spp., Salmonella spp., street-vendor

\section{INTRODUCTION}

Ready-to-eat food and beverages sold by street hawkers are known as street-vended foods. Street food has been gaining popularity worldwide due to its unique taste, variety, and low price (Shagufta et al., 2017). Street hawkers commonly sell their food products in small stalls, portable tables, food trucks, or pushcarts (Das et al., 2010). However, the consumption of street-vended food and beverages increases the risk of foodborne diseases (Tambekar et al., 2009). There are many concerns surrounding the safety of street-vended food prepared by hawkers. In particular, street-vended food and drinks are usually synonymous with poor facilities. Besides, the hawkers do not have any environmental controls such as temperature and humidity control to guarantee the security or safety of their food products (Nawawee et al., 2019).

Food handlers are the primary source of contamination for foodborne diseases, as they can easily spread the bacteria to the food, especially via the faecal-oral route, open wounds, and dirty food contact surfaces (Abdul-Mutalib et al., 2015). In Malaysia, of every 100000 individuals, roughly 60.28 cases have been diagnosed with food and waterborne diseases, with typhoid fever being the most predominant (Woh et al., 2017). Salmonella spp. is a known foodborne pathogen that could also be found in drinking water and natural water resources (De Cesare, 2018; Shagufta et al., 2017; Tunung et al., 2007). In contrast, Citrobacter spp. are more commonly known as an opportunistic, nosocomial infection-causing microorganism that can be found in animal and human gastrointestinal, respiratory, and urinary tracts, and also in water and soil environments and food products (Trivedi et al., 2015). Although the presence of Citrobacter spp. in food products may not be routinely monitored due to its low incidence in Malaysia, this microorganism has been implicated in foodborne outbreaks elsewhere (Aminharati et al., 2019; Pletz et al. 2018; Tschape et al., 1995).

Bacterial infections can usually be treated with antibiotics. However, many bacterial strains have developed antibiotic resistance. Past studies in Malaysia have reported a high percentage of antibiotic resistance in pathogens isolated from food samples (Bahri et al., 2019; Chin et al., 2018; Odeyami \& Sani, 2016; Tunung et al., 2007). The seriousness of this issue was further propounded by the World Health Organisation (WHO) declaring antibiotic resistance to be one of the most important public health threats of the 21 st century.

This study tested for the presence of Salmonella spp. and Citrobacter spp. in drinks sold in the Chow Kit district in Kuala Lumpur, Malaysia. Presumptive isolates were then 
confirmed via biochemical testing followed by $16 \mathrm{~S}$ rRNA PCR and sequencing to further identify the bacteria. Then, the isolates' antimicrobial resistance to selected antibiotics was assessed.

\section{MATERIALS AND METHODS}

\section{Sample Collection}

Sampling procedures were as described in our previous study (Nawawee et al., 2019). Chow Kit, Kuala Lumpur, Malaysia was chosen as the sampling site due to its popularity among the locals and tourist for its markets and trading bazars. The sampling location was also located within $1 \mathrm{~km}$ distance from the research laboratory. The sample inclusion criteria were the drinks were kept in uncapped container before being poured into small plastic bags with ties cups purchased by the customer. This study did not include bottled, pre-packaged, or canned drinks. There were 17 street vendors that sold beverages that fitted these criteria. A total of 31 beverages comprising fresh fruit juice (sugarcane, coconut, watermelon) $(n=11)$, cordial-based drinks $(n=11)$, and milk-based drinks $(n=9)$ were purchased. Each sample were purchased on different days between 10-11 am. The drinks bought were kept in their normal packaging, placed in an icebox at $4^{\circ} \mathrm{C}$, then moved to the laboratory and examined within the same day.

\section{Experimental Procedures}

All beverage samples were subjected to bacterial isolation of using culture method (Chong et al., 2017a; Thung et al., 2018). Presumptive isolates obtained from this method were then confirmed via Gram-staining procedures, a series of biochemical test as well as species identification via Polymerase Chain Reaction (PCR) method. All isolates were also subjected to antibiotic susceptibility test to determine the presence of resistant bacteria in the beverage samples.

\section{Bacterial Isolation from Beverage Samples}

Isolation of presumptive Salmonella spp. and Citrobacter spp. were conducted based on methods by Chong et al. (2017a) and Thung et al. (2018) with some modifications. First, $10 \mathrm{ml}$ of the samples were homogenized with an equivalent volume of buffered peptone water (BPW) (Merck, Germany). A pre-enrichment step was then conducted, involving a 20 -hr incubation of the sample at $37^{\circ} \mathrm{C}$. Next, $10 \mathrm{ml}$ of Rappaport-Vassiliadis soy broth (RVS broth) (Merck, Germany) was prepared to which a $0.1 \mathrm{ml}$ aliquot of the pre-enriched samples were added. The mixture was then vortexed followed by a $24-\mathrm{hr}$ incubation at $41.5^{\circ} \mathrm{C}$. This step was followed with streaking a loopful of the enriched suspension onto Xylose Lysine Deoxycholate (XLD) agar (Merck, Germany) in triplicates, and 24-hr 
incubation at $37^{\circ} \mathrm{C}$. All black colonies or red colonies with black centres were considered as positive results in this study. Two colonies from each positive beverage sample were further analysed. For further analysis, isolated colonies were streaked onto Nutrient Agar (Merck, Germany) followed by $24-\mathrm{hr}$ incubation at $37^{\circ} \mathrm{C}$. A standard Gram-staining procedure was also conducted on the isolates.

\section{Biochemical Test}

Biochemical test for confirmation of the presumptive isolates was done using a Microgen GN-ID (GN A + B) system (Microgen Bioproducts Ltd, UK) in accordance with the manufacturer's procedure. In brief, a single colony from an 18-24 hr culture on Nutrient Agar was emulsified in $0.85 \%$ saline. A total of $0.1 \mathrm{ml}$ of the bacterial suspension was then added to each well of the microwell test strips and incubated at $37^{\circ} \mathrm{C}$ for $18-24$ hours. Additional reagents were added, and all colour changes were recorded according to the colour code provided by the manufacturer. Interpretations of the result and species identification were made using Microgen ID Software (MID-60).

\section{Identification of Isolates via Polymerase Chain Reaction (PCR)}

All isolates were grown in Nutrient Agar (Merck, Germany) for $18-24$ hours at $37^{\circ} \mathrm{C}$. DNA from the overnight culture was extracted using the boiling method (Zulfakar et al., 2019). A few loopful of bacterial culture were inoculated into $500 \mu 1$ sterile distilled water. The suspension was then boiled at $95^{\circ} \mathrm{C}$ for 10 minutes, and quickly cooled at $-20^{\circ} \mathrm{C}$ freezer for 10 minutes. Then, the suspension was centrifuged at $12000 \times \mathrm{g}$ for 5 minutes. The purity of the DNA template was determined by using a NanoDrop spectrophotometer (Thermoscientific, Model 2000) at $\mathrm{A}_{260 / 280}$ and $\mathrm{A}_{260 / 230}$. The supernatant containing DNA was used as the DNA template solution for PCR.

The 16S rDNA PCR was conducted using the universal primers, 27f (5'-AGA GTT TGA TCC TGG CTG AG-3') and 1492r (5'-GGT TAC CTT GTT ACG ACT T-3'), with the expected base pair of $1380 \mathrm{bp}$ (Suardana, 2014). Amplification was carried out in a $50 \mu \mathrm{l}$ reaction mixtures containing $5 \mu \mathrm{l}$ of each primer, $25 \mu \mathrm{l}$ of 1 X PCR Master Mix (First Base Asia, Singapore), $5 \mu \mathrm{l}$ DNA template and $10 \mu \mathrm{l}$ sterile distilled water. Next, amplification was applied on the mixture for 35 cycles, in a thermal cycler (Thermo Fisher Scientific, USA). Before the first cycle, the mixture was denatured for $2 \mathrm{~min}$ at $94^{\circ} \mathrm{C}$. Each cycle comprised $1 \mathrm{~min}$ denaturation at $94^{\circ} \mathrm{C}, 1 \mathrm{~min}$ annealing at $45^{\circ} \mathrm{C}, 2 \mathrm{~min}$ elongation at $72^{\circ} \mathrm{C}$, and a $10 \mathrm{~min}$ final elongation at $72^{\circ} \mathrm{C}$. Next, $3 \mu \mathrm{l}$ of the amplified PCR products were electrophoresed on $1 \%(\mathrm{wt} / \mathrm{vol})$ agarose gel at $70 \mathrm{~V}$ for 30 minutes, pre-stained with non-ethidium bromide nucleic acid stain (First Base Asia), and then visualised under UV light using a UV transilluminator. The amplified products were then sent to First Base Sdn. Bhd., Malaysia, for DNA sequencing. The sequencing results were interpreted and 
compared with the NCBI database using Basic Local Alignment Search Tool (BLAST) software.

\section{Antibiotic Susceptibility Test}

Standard Kirby-Bauer disc diffusion method (CLSI, 2012) was used to determine the antibiotic susceptibility of the isolates. First, 3-5 isolated colonies from a 24 hrs culture at $37^{\circ} \mathrm{C}$ on Nutrient Agar were chosen for each bacterial strain and transferred into $5 \mathrm{ml}$ Mueller Hinton broth (Merck, Germany). The broth was then incubated at $37^{\circ} \mathrm{C}$ for $2 \mathrm{hrs}$ and the turbidity of the culture were determined using a light spectrophotometer (PRIM 3649 Secomam, France) at $625 \mathrm{~nm}$. Then, the cultures with optical density readings between 0.08 $0.13 \mathrm{~nm}$ were swabbed with a sterile cotton swab on Mueller Hinton Agar (MHA) plates (Merck, Germany) and left to dry for approximately 2 minutes. Following that, antibiotic discs were placed on the plates. The antibiotics tested were erythromycin (15 $\mu \mathrm{g}, \mathrm{E} 15)$, penicillin (10 $\mu \mathrm{g}, \mathrm{P} 10)$, chloramphenicol (30 $\mu \mathrm{g}, \mathrm{C} 30)$, sulfamethoxazole-trimethoprim (25 $\mu \mathrm{g}$, SXT25), tetracycline (30 $\mu \mathrm{g}$, TE30), amoxycillin (25 $\mu \mathrm{g}$, AML25), ampicillin (10 $\mu \mathrm{g}$, AMP10), cephalexin (30 $\mu \mathrm{g}$, CL30), cefoxitin (30 $\mu \mathrm{g}$, FDX30), cefotaxime (30 $\mu \mathrm{g}$, CTX30), and ceftriaxone ( $30 \mu \mathrm{g}, \mathrm{CRO} 30)$. After $24 \mathrm{hrs}$ of incubation at $37^{\circ} \mathrm{C}$, the isolates were rated as susceptible, intermediate, or resistant based on the measured inhibition zones. Finally, the formula below (Krumperman, 1983; Al-Dulaimi et al., 2019) was used to determine the multiple antibiotic resistance (MAR) index for each resistance pattern:

\section{Multiple antibiotic resistance $(M A R)$ index $=$ \\ Number of antibiotics to which a particular isolate was resistant (a) Total number of antibiotics tested $(b)$}

\section{RESULTS AND DISCUSSION}

Out of 31 beverage samples tested, only $6(19 \%)$ beverage samples were found positive for presumptive Salmonella and Citrobacter spp. based on the early identification on XLD agar. All positive samples showed pale to red colonies with black pigmentation in the centre of the colony. Although we have previously reported that milk-based drinks had the highest average total viable counts as compared to the other beverages (Nawawee et al., 2019), all of the milk-based drinks tested negative for both species in the current study. Meanwhile, cordial-based drinks and fruit juices each contributed three positive samples. Detection of pathogenic enterobacteriaceae bacteria have been reported in previous studies (Parish, 2008; Tribst et al., 2009). As fruits used to produce juices commonly do not undergo any heat treatments, therefore it is easily contaminated by microorganisms thus contaminating the beverages to be sold. Contamination of fruit juices could also occur due 
to cross-contamination from the juice extractors and as well as utensils used to prepare the beverages (Chong et al., 2017b). Other possible sources that may contribute to the different results between the three type of beverages could be due to the handling practices by the street-vendors themselves as these beverages were bought from different street-vendors. Knowledge and application of safe food handling practices by the food handlers are essential in maintain the safety of food products sold to the consumers (Odeyami et al., 2019).

Gram-staining procedure confirmed that all strains are Gram-negative bacteria. Upon confirmation using the biochemical testing procedure with the commercial kit, it was identified that only 1 out of the 12 isolates was Salmonella spp. whereas the other isolates were positively identified as Citrobacter spp. (Table 1). Identification via the $16 \mathrm{~S}$ rDNA PCR method further confirmed these results (Table 2). The isolated Salmonella strain was identified as Salmonella enterica subsp. enterica serovar Derby, whereas the other isolates were identified as Citrobacter werkmanii (9 isolates) and Citrobacter freundii (1 isolate), while the exact species for the remaining Citrobacter isolates are unknown.

Three critical characteristics are essential in the differentiation of Salmonella spp. colonies from Citrobacter spp. colonies on XLD agar; the ability to ferment xylose, the production of hydrogen sulphide, and the presence of lysine decarboxylase activity. Both Salmonella spp. and Citrobacter spp. are xylose fermenters that will cause acidification of the media to occur, causing the colour of the medium to change to yellow. Production of hydrogen sulphide would occur in Salmonella spp. and some Citrobacter spp., indicated by the presence of black pigmentation at the centre of the colonies. Lysine decarboxylase activities in Salmonella spp. strains will lead to cadaverine built-up causing alkalisation, thus neutralising the acidic condition caused by xylose degradation; hence, changing the media's colour back to red. The absence of this lysine decarboxylase reaction would cause the media colour to remain yellow (Powell \& Marcon, 2012; Reller, 2012).

The presence of Salmonella spp. and Citrobacter spp. in street-vended beverages sold in the Chow Kit area may be attributed to the use of contaminated water sources that the vendors use to prepare their products (Levantesi et al., 2012). These microorganisms can be present as biofilm in the water distribution system and may be dispersed when the water from this distribution system is used to make beverages, as well as to wash vending utensils (Nemo et al., 2017). Lack of a freshwater supply system at every stall as observed in this study has forced some of the vendors to obtain their water supply elsewhere and they tend to keep any water they have in containers near the stall. If the safety of the stored water is not maintained, it can become contaminated. Apart from that, microorganisms could also be present in the edible ice served together with the beverages sold (Sunday et al., 2011).

Lack of hygienic control of the vending site and its surrounding area could also be one of the contributing factors of the presence of these microorganisms. We have reported previously that the cleanliness of the vending sites is not up to par (Nawawee et al., 2019). We also observed that the presence of uncovered trash cans was common at all stalls, which, 


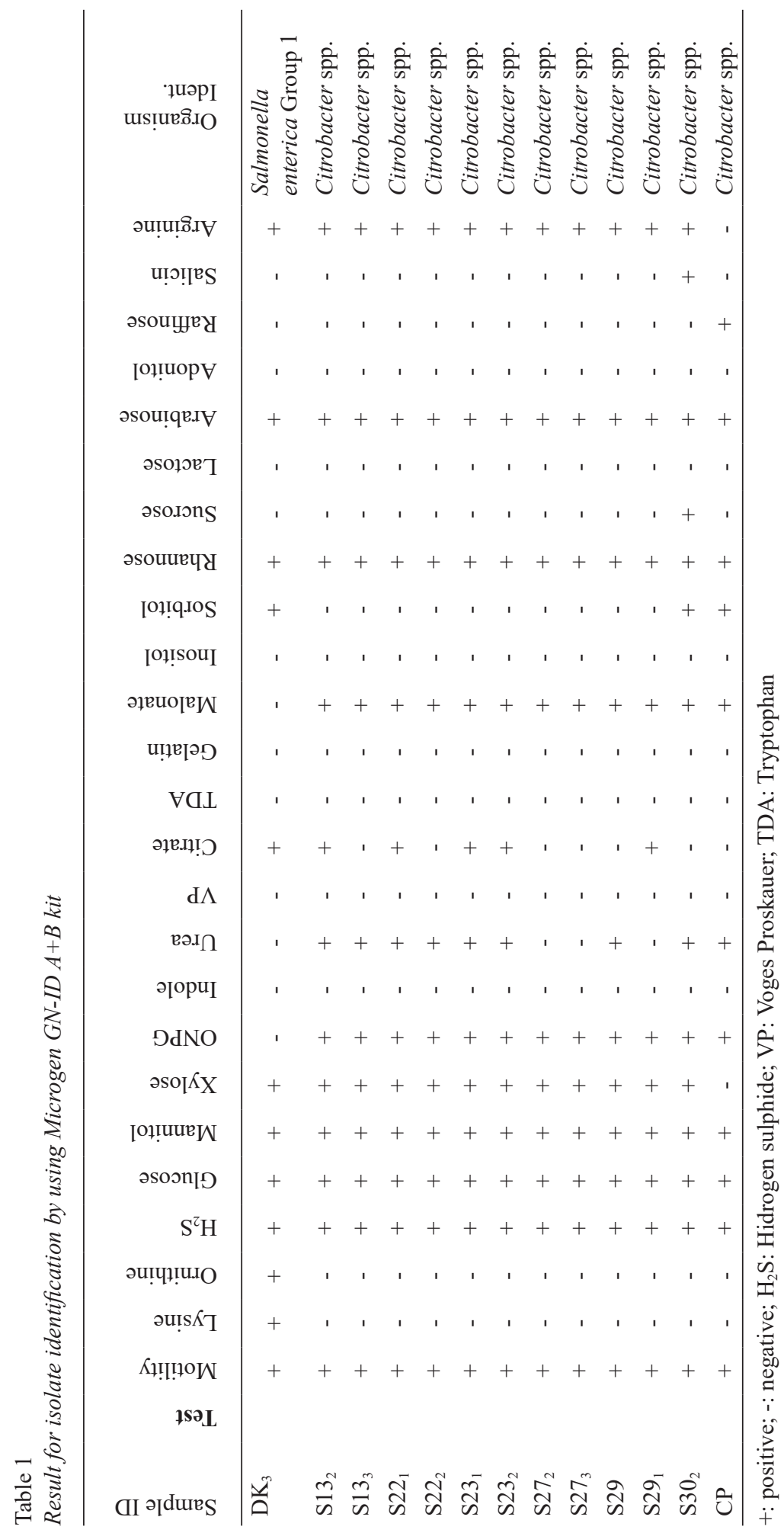

Pertanika J. Sci. \& Technol. 29 (1): 593 - 606 (2021) 
Table 2

Bacterial identification of isolates via $16 S$ rDNA PCR method

\begin{tabular}{llc}
\hline Isolate ID & \multicolumn{1}{c}{ Bacterial species } & \% Ident. \\
\hline $\mathrm{DKI}_{3}$ & $\begin{array}{l}\text { Salmonella enterica subsp. enterica serovar Derby strain SeqrSC0080 16S } \\
\text { ribosomal RNA gene, partial sequence }\end{array}$ & $99.20 \%$ \\
$\mathrm{~S}_{3} 3_{2}$ & Citrobacter werkmanii strain BF-6, complete genome & $99.93 \%$ \\
$\mathrm{~S}_{3} 3_{3}$ & Citrobacter freundii strain F-CF1 16S ribosomal RNA gene, partial sequence & $99.39 \%$ \\
$\mathrm{~S}_{2} 2_{1}$ & Citrobacter werkmanii strain BF-6, complete genome & $99.78 \%$ \\
$\mathrm{~S} 22_{2}$ & Citrobacter werkmanii strain BF-6, complete genome & $99.71 \%$ \\
$\mathrm{~S} 23_{1}$ & Citrobacter werkmanii strain BF-6, complete genome & $99.70 \%$ \\
$\mathrm{~S} 23_{2}$ & Citrobacter werkmanii strain BF-6, complete genome & $99.93 \%$ \\
$\mathrm{~S} 27_{2}$ & Citrobacter werkmanii strain BF-6, complete genome & $99.85 \%$ \\
$\mathrm{~S} 27_{3}$ & Citrobacter sp. UIWRF1266 16S ribosomal RNA gene, partial sequence & $98.18 \%$ \\
$\mathrm{~S} 29$ & Citrobacter werkmanii strain BF-6, complete genome & $99.70 \%$ \\
$\mathrm{~S} 29_{1}$ & Citrobacter werkmanii strain BF-6, complete genome & $99.93 \%$ \\
$\mathrm{~S} 30_{2}$ & Citrobacter werkmanii strain BF-6, complete genome & $99.85 \%$ \\
\hline
\end{tabular}

in turn, attracted pests such as flies to the area; thus disseminating microorganisms to the entire stall and inevitably to the beverages as well. The location of these vending sites at the roadside, the lack of adequate facilities for the vendors to wash their hands and to clean their vending area, and the lack of food hygiene practices among the vendors as observed by this study, will further expose the sold products to the risk of contamination as supported with findings by Andargie et al. (2008), Levantesi et al. (2012), and Odeyami et al. (2019).

Capita and Alonso-Calleja (2013) pointed out a major concern regarding the transmission of resistant bacteria through the food supply chain. Moreover, based on the results of the antibiotic susceptibility testing, all tested Salmonella and Citrobacter isolates showed resistance to penicillin and erythromycin (Table 3). Figure 1 shows a representative

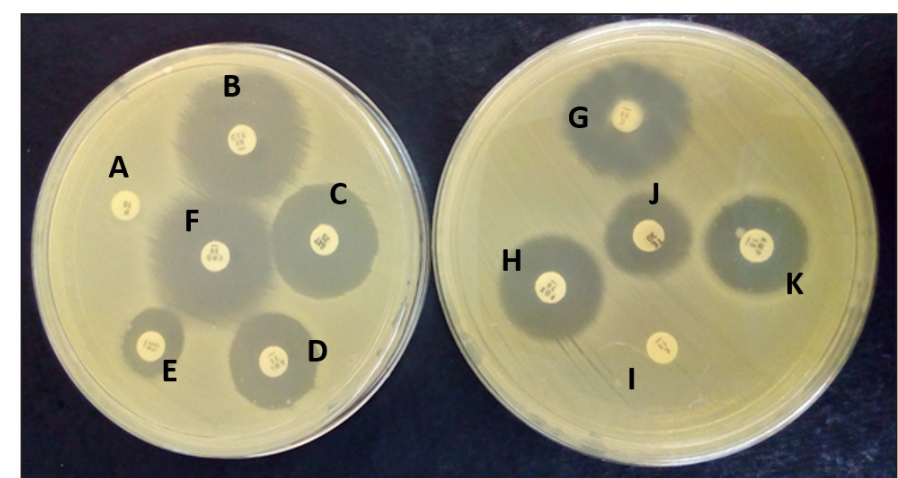

Figure 1. Antibiotic susceptibility testing result for S29, (Citrobacter werkmanii). A- Penicillin; B-Ceftriaxone; C- Trimethoprim-sulfamethoxazole; D-Ampicilin; E- Tetracycline; F- Cefotaxime; G-Chloramphenicol; H-Amoxycilin; I- Erythromycin; J- Cephalexin; K- Cefoxitin. 
Antibiotic Resistance Bacteria in Street-vended Beverages

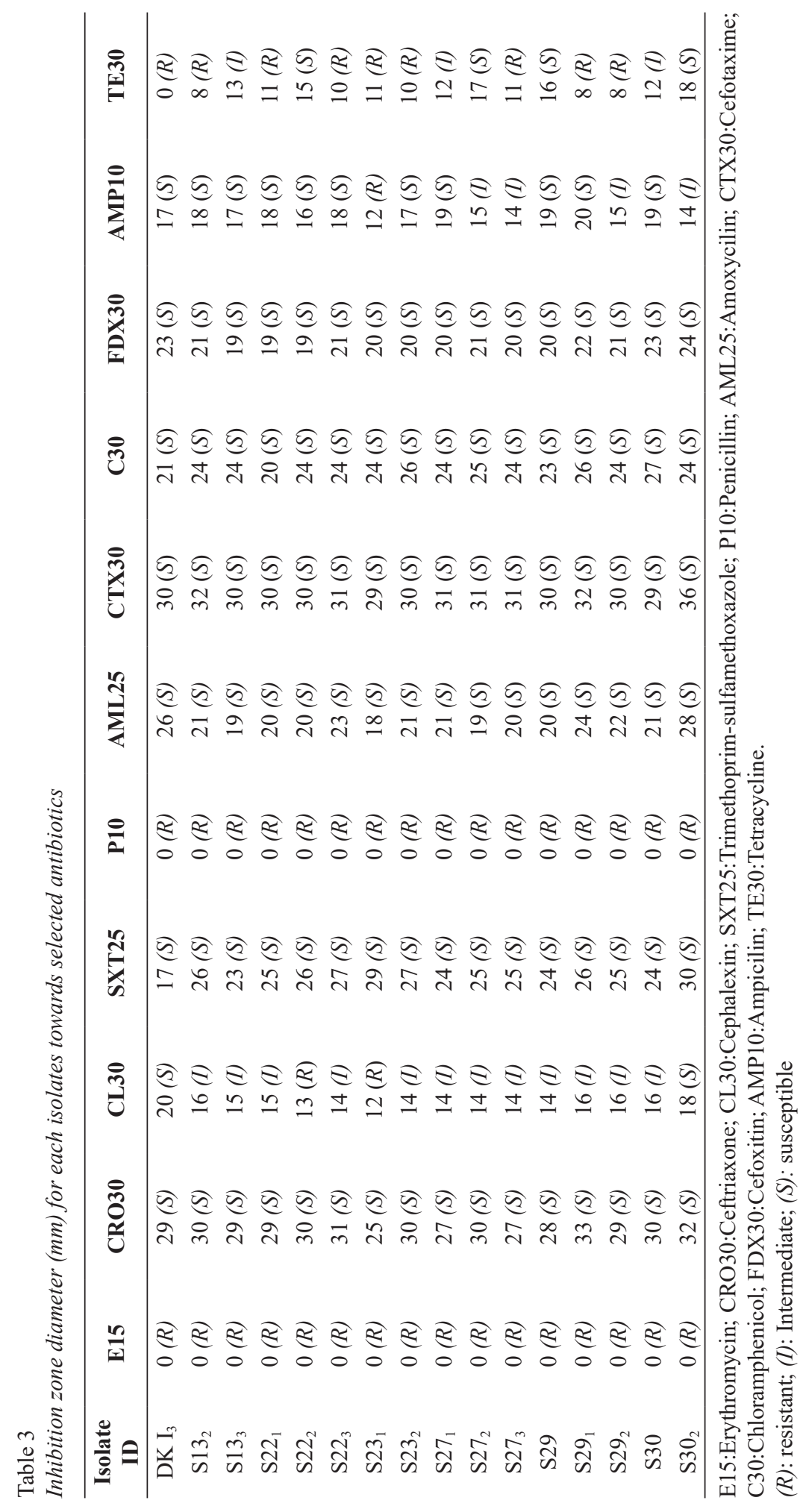

Pertanika J. Sci. \& Technol. 29 (1): 593 - 606 (2021) 
Table 4

Antibiotic resistance profile for all tested bacterial isolates $(n=12)$

\begin{tabular}{lcc}
\hline \multirow{2}{*}{ Antibiotic } & \multicolumn{2}{c}{ Bacterial isolates antibiogram profile } \\
\cline { 2 - 3 } & Resistant (\%) & Sensitive (\%) \\
\hline Penicilin (P10) & $12(100)$ & $0(0)$ \\
Erythromycin (E15) & $12(100)$ & $0(0)$ \\
Ampicillin (AMP10) & $1(8.3)$ & $11(91.7)$ \\
Tetracycline (TE30) & $7(58.3)$ & $5(41.7)$ \\
Cephalexin (CL30) & $2(16.7)$ & $10(83.3)$ \\
Amoxicillin (AML25) & $0(0)$ & $12(100)$ \\
Chloramphenicol (C30) & $0(0)$ & $12(100)$ \\
Trimetoprim-sulfamethoxazole (SXT25) & $0(0)$ & $12(100)$ \\
Cefoxitin (FDX30) & $0(0)$ & $12(100)$ \\
Cefotaxime (CTX30) & $0(0)$ & $12(100)$ \\
Ceftriaxone (CRO30) & $0(0)$ & $12(100)$ \\
\hline
\end{tabular}

Table 5

Multiple Antibiotic Resistance (MAR) Index profile of tested bacterial isolates $(n=12)$

\begin{tabular}{lcc}
\hline \multicolumn{1}{c}{ Isolate ID } & Antibiotic Resistance Profile & MAR Index \\
\hline $\mathrm{S}_{13}, \mathrm{~S}_{2} 7_{2}, \mathrm{~S} 29, \mathrm{~S} 30_{2}$ & E15, P10 & 0.18 \\
$\mathrm{~S} 22_{2}$ & E15, P10, CL30 & 0.27 \\
$\mathrm{DKI}_{3}, \mathrm{~S} 13_{2}, \mathrm{~S} 22_{1}, \mathrm{~S} 23_{2}, \mathrm{~S} 27_{3}, \mathrm{~S} 29_{1}$ & E15, P10, TE30 & 0.27 \\
$\mathrm{~S}_{2} 3_{1}$ & E15, P10, TE30, CL30, AMP10 & 0.45 \\
\hline
\end{tabular}

E15: Eryhtromycin $(15 \mu \mathrm{g})$; P10: Penicillin $(10 \mu \mathrm{g})$; CL30: Cephalexin $(30 \mu \mathrm{g})$; TE30: Tetracycline $(30 \mu \mathrm{g})$; AMP10: Ampicillin $(10 \mu \mathrm{g})$

sample of the conducted antibiotic susceptibility testing. In particular, seven $(58.3 \%)$ isolates were found resistant to tetracycline, two (16.7\%) isolates exhibited resistance to cephalexin, and one (8.3\%) was resistant to ampicillin (Table 4). Nevertheless, all of the isolates were sensitive to amoxicillin, chloramphenicol, trimethoprim-sulfamethoxazole, cefoxitin, cefotaxime, and ceftriaxone. The S23 (Citrobacter werkmanii) isolate exhibited the highest Multiple Antibiotic Resistance (MAR) index profile (0.45), signifying its resistance to five of the antibiotics tested (Table 5). Other than that, six isolates showed a MAR index of 0.27 (resistant toward 3 antibiotics) and the isolates with the lowest MAR index (0.18) recorded resistance to only two of the antibiotics. Bacterial isolates with a MAR index higher than 0.20 indicates that the isolate originated from an environment where various antibiotics were used.

High level of resistance showed by the isolates toward penicillin and erythromycin might be due to the widespread use of these antibiotics in the clinical setting (Fair \& Tor, 2014). This resistance pattern is a result of selective pressures of antimicrobial use, changes in microbial characteristics, and technological changes that enhanced the modern 
development and transmission of drug-resistant microbes (Walsh, 2000). It is important to note that the isolates from street food showed $83.3 \%$ multidrug-resistant toward three or more antibiotics compared to clinical samples (Tunung et al., 2007). The isolated Salmonella Derby strain in this study showed resistance toward tetracycline. High frequency of resistant Salmonella strains isolated from food in Malaysia toward tetracycline has been reported ranging from $72.7 \%$ to $77.3 \%$ (Thong \& Modarressi, 2011).

In this study, the Citrobacter isolates showed resistance toward penicillin, erythromycin, cephalexin, tetracycline, and ampicillin. This finding was in concordance with studies by Leski et al. (2016) and Liu et al. (2017) who also reported the same finding, noting the resistance of Citrobacter spp. to many classes of antibiotics including $\beta$-lactam, tetracycline, and macrolides. Yang et al. (2018) also reported the resistance of Citrobacter spp. to almost all tested antibiotics, including aminoglycosides, cephalosporin, carbapenem, fluoroquinolone, and sulphonamide but the bacteria was still susceptible to tetracycline. However, the current findings show that except for cephalexin, 100\% of the Citrobacter spp. isolates were sensitive to the later generation of cephalosporin, namely cefoxitin, cefotaxime, and ceftriaxone.

\section{CONCLUSION}

In conclusion, although the number of samples in this study may be limited, this study showed the presence of microbial contamination in street-vended beverages and revealed that Citrobacter spp. as having a potential role as an emerging multidrug-resistant bacterial species in the food production system. These findings also demonstrated the possible risk of street-vended beverages as a medium for the dissemination of antibiotic-resistant bacteria to the population. Besides the fundamental aspect of food safety and hygiene practices, awareness of the danger of antibiotic-resistant spread in food products should also be emphasised in the food safety training received by food handlers.

\section{ACKNOWLEDGEMENT}

Universiti Kebangsaan Malaysia provided partial support for this research under the GP2019-K016381 fund scheme.

\section{REFERENCES}

Abdul-Mutalib, N., Syafinaz, A., Sakai, K., \& Shirai, Y. (2015). An overview of foodborne illness and food safety in Malaysia. International Food Research Journal, 22(3), 896-901.

Al-Dulaimi, M. M. K., Mutalib, S. A., Ghani, M. A., Zaini, N. A. M., \& Ariffin, A. A. (2019). Multiple antibiotic resistance (MAR), plasmid profiles, and DNA polymorphisms among Vibrio vulnificus isolates. Antibiotics, 8(2), 1-13. doi: https://doi.org/10.3390/antibiotics8020068 
Aminharati, F., Ehrampoush, M. H., Dallal, M. M. S., Yaseri, M., Tafti, A. A. D., \& Rajabi, Z. (2019). Citrobacter freundii foodborne disease outbreaks related to environmental conditions in Yazd province, Iran. Iran Journal of Public Health, 48(6), 1099-1105.

Andargie, G., Kassu, A., Moges, F., Tiruneh, M., \& Huruy, K. (2008). Prevalence of bacteria and intestinal parasites among food handlers in Gondar Town, Northwest Ethiopia. Journal of Health, Population and Nutrition, 26(4), 451-455. doi: 10.3329/jhpn.v26i4.1887

Bahri, A. A., Salleh, W., Lani, M. N., \& Abdullah, W. Z. W. (2019). Antimicrobial resistance of Escherichia coli isolated of ulam from supermarkets and wet markets in Kuala Terengganu, Malaysia. Malaysian Applied Biology, 48(3), 35-42.

Capita, R., \& Alonso-Calleja, C. (2013). Antibiotic-resistant bacteria: A challenge for the food industry. Critical Reviews in Food Science and Nutrition, 53(1), 11-48. doi: https://doi.org/10.1080/10408398.2010.519837

Chin, P. S., Ang, G. Y., Yu, C.Y., Tan, E. L., Tee, K. K, Yin, W. F., .. \& \& Tan, G. Y. A. (2018). Prevalence, antimicrobial resistance, and genetic diversity of Listeria spp. isolated from raw chicken meat and chicken-related products in Malaysia. Journal of Food Protection 81(2), 284-289. doi: https://doi. org/10.4315/0362-028X.JFP-17-186

Chong, E. S., Bidin, Z. F., Bakar, N. F. A., \& Zulfakar, S. S. (2017a). Bacterial contamination on beef carcass at selected abattoirs located in Selangor Malaysia. Malaysian Applied Biology, 46(1), 37-43

Chong, S. Y., Rao, P. V., \& Soon, J. M. (2017b). Identification of Escherichia spp. strains in street-vended beverages and associated preparation surfaces using 16S rRNA analysis. International Food Research Journal, 24, 1811-1818.

Das, A., Nagananda, G. S., Bhattacharya, S., \& Bhardwaj, S. (2010). Microbiology quality of street-vended Indian chaats sold in Bangalore. Journal of Biological Sciences, 10(3), 255-260.

De Cesare, A. (2018). Salmonella in Foods: A reemerging problem. Advances in Food and Nutrition Research, 86, 137-179. doi: https://doi.org/10.1016/bs.afnr.2018.02.007

Fair, R. J., \& Tor, Y. (2014). Antibiotics and bacterial resistance in the 21st century. Perspectives in Medicinal Chemistry, 6, 25-64. doi: https://doi.org/10.4137/PMC.S14459

Krumperman, P. H. (1983). Multiple antibiotic resistance indexing of Escherichia coli to identify high-risk sources of fecal contamination of foods. Applied and Environmental Microbiology, 46(1), 165-170.

Leski, T. A., Taitt, C. R., Bangura, U., Stockelman, M. G., Ansumana, R., Cooper, W. H., ... \& Vora, G. J. (2016). High prevalence of multidrug-resistant Enterobacteriaceae isolated from outpatient urine samples but not the hospital environment in Bo, Sierra Leone. BMC Infectious Disease, 16(1), 1-9. doi: https:// doi.org/10.1186/s12879-016-1495-1

Levantesi, C., Bonadonna, L., Briancesco, R., Grohmann, E., Toze, S., \& Tandoi, V. (2012). Salmonella in surface and drinking water: Occurrence and water-mediated transmission. Food Research International, 45(2), 587-602. doi: https://doi.org/10.1016/j.foodres.2011.06.037

Liu, L., Lan, R., Liu, L., Wang, Y., Zhang, Y., Wang, Y., \& Xu, J. (2017). Antimicrobial resistance and cytotoxicity of Citrobacter spp. in Maanshan Anhui Province, China. Frontiers in Microbiology, 8, 1-12. doi: https://doi.org/10.3389/fmicb.2017.01357 
Nawawee, N. S. M., Bakar, N. F. A., \& Zulfakar, S. S. (2019). Microbiological safety of street-vended beverages in Chow Kit, Kuala Lumpur. International Journal of Environmental Research and Public Health, 16, 4463-4471. doi: https://doi.org/10.3390/ijerph16224463

Nemo, R., Bacha, K., \& Ketema, T. (2017). Microbiological quality and safety of some-street vended foods in Jimma Town, Southwestern Ethiopia. African Journal of Microbiology Research, 11(14), 574-585. doi: https://doi.org/10.5897/AJMR2014.7326

Odeyami, O. A., \& Sani, N. A. (2016). Antibiotic resistance and burden of foodborne diseases in developing countries. Future Science OA, 2(4), 1-4. doi: https://doi.org/10.4155/fsoa-2016-0023

Odeyami, O. A., Sani, N. A., Obadina, A. O., Saba, C. K. S., Bamidele, F. A., Abughoush, M., ... \& Aberoumand, A. (2019). Food safety knowledge, attitudes and practices among consumers in developing countries: An international survey. Food Research International, 116, 1386-1390. doi: https://doi.org/10.1016/j. foodres.2018.10.030

Parish, M. E. (2008). Food safety issues and the microbiology of fruit beverages and bottled water. In N. Heredia, I. Wesley \& S. Garcia, (Eds.), Microbiologically safe foods (pp. 291-304). New York, USA: JohnWiley \& Sons. doi: 10.1002/9780470439074

Pletz, M. W., Wollny, A., Dobermann, U., Rödel, J., Neubauer, S., Stein, C., .. \& Maschmann, J. (2018). A nosocomial foodborne outbreak of a VIM carbapenemase-expressing Citrobacter freundii. Clinical Infectious Diseases, 67(1), 58-64. doi: https://doi.org/10.1093/cid/ciy034

Powell, D. A., \& Marcon, M. J. (2012). Etiologic agents of infectious diseases: Citrobacter species. In S. S. Long, L. K. Pickering \& C. G. Prober (Eds.), Principles and practice of pediatric infectious diseases (pp. 806-807.). Edinburgh, NY: Elsevier.

Reller, M. E. (2012). Etiologic agents of infectious diseases: Salmonella species. In S. Long, L. Pickering \& C. Prober (Eds.), Principles and practice of pediatric infectious diseases (pp. 814-819). Philadelphia, USA: Saunders (Imprint).

Shagufta, B., Sivakumar, M., Kumar, S., Agarwal, R. K., Bhilegaonkar, K. N., Kumar, A., \& Dubal, Z. B. (2017). Antimicrobial resistance and typing of Salmonella isolated from street vended foods and associated environment. Journal of Food Science and Technology, 54(8), 2532-2539. doi: https://doi.org/10.1007/ s13197-017-2698-1

Suardana, I. W. (2014). Analysis of nucleotide sequences of the 16S rRNA gene of novel Escherichia coli strains isolated from feces of human and Bali cattle. Journal of Nucleic Acids, 2014, 1-7. doi: https://doi. org/10.1155/2014/475754

Sunday, P. U., Nyaudoh, U. N., \& Etido, J. U. (2011). Microbiological quality and safety evaluation of fresh juices and edible ice sold in Uyo Metropolis, South-South, Nigeria. International Journal of Food Safety, $13,374-378$.

Tambekar, D. H., Jaiswal, V. J., Dhanorkar, D. V., Gulhane, P. B., \& Dudhane, M. N. (2009) Microbial quality and safety of street vended fruit juices: A case study of Amravati City. International Journal of Food Safety, 10, 72-76. 
Thong, K. L., \& Modarressi, S. (2011). Antimicrobial resistance genes associated with Salmonella from retail meats and street foods. Food Research International, 44(9), 2641-2646. doi: https://doi.org/10.1016/j. foodres.2011.05.013

Thung, T. Y., Radu, S., Mahyudin, N. A., Rukayadi, Y., Zakaria, Z., Mazlan, N., ... \& Chin, Y. Z. (2018). Prevalence, virulence genes and antimicrobial resistance profiles of Salmonella serovars from retail beef in Selangor, Malaysia. Frontiers in Microbiology, 8, 1-8. doi: https://doi.org/10.3389/fmicb.2017.02697

Tribst, A. A. L., Sant'Ana, A. S., \& Massaguer, P. R. (2009). Review: Microbiological quality and safety of fruit juices-past, present and future perspectives. Critical Reviews in Microbiology, 35, 310-339. doi: https://doi.org/10.3109/10408410903241428

Trivedi, M. K., Branton, A., Trivedi, D., Nayak, G., Mondal, S. C., \& Jana, S. (2015). Phenotyping and 16S rDNA analysis after biofield treatment on Citrobacter braakii: A urinary pathogen. Journal of Clinical and Medical Genomics, 3(1), 1-8. doi: https://hal.archives-ouvertes.fr/hal-01435926

Tschape, H., Prager, R., Streckel, W., Fruth, A., Tietze, E., \& Böhme, G. (1995). Verotoxinogenic Citrobacter freundii associated with severe gastroenteritis and cases of haemolytic uremic syndrome in a nursery school: Green butter as the infection source. Epidemiology Infections, 114(3), 441-450. doi: https://doi. org/10.1017/S0950268800052158

Tunung, R., Chai, L., Usha, M., Lee, H., Fatimah, A., Farinazleen, M., \& Son, R. (2007). Characterization of Salmonella enterica isolated from street food and clinical samples in Malaysia. ASEAN Food Journal, 14(3), 161-173.

Walsh, C. (2000). Molecular mechanisms that confer antibacterial drug resistance. Nature, 406(6797), 775781. doi: https://doi.org/10.1038/35021219

Woh, P. Y., Thong, K. L., Behnke, J. M., Lewis, J. W., \& Zain, S. N. M. (2017). Characterization of nontyphoidal Salmonella isolates from asymptomatic migrant food handlers in Peninsular Malaysia. Journal of Food Protection, 80(8), 1378-1383. doi: https://doi.org/10.4315/0362-028X.JFP-16-342

Yang, L., Li, P., Liang, B., Hu, X., Li, J., Xie, J., ... \& Song, H. (2018). Multidrug-resistant Citrobacter freundii ST139 co-producing NDM-1 and CMY-152 from China. Scientific Reports, 8(1), 1-7. doi: https://doi. org/10.1038/s41598-018-28879-9

Zulfakar, S. S., Abu-Bakar, N. F., Aidilputra, A. A., Miatong, A., \& Chong, E. S. (2019). Microbial contamination of meat contact surfaces at the selected beef processing plants in Selangor and its biofilm formation ability. Pertanika Journal of Tropical Agricultural Science, 42(2), 709-726. 